\title{
Sex- and Age-dependent Effects of Orexin 1 Receptor Blockade on Open-Field Behavior and Neuronal Activity
}

\author{
Shannon R. Blume ${ }^{\# a}$, Hannah Nam ${ }^{\# a}$, Sandra Luz ${ }^{a}$, Debra A. Bangasserc, and Seema \\ Bhatnagara,b, \\ aDepartment of Anesthesiology and Critical Care Medicine, Children's Hospital of Philadelphia, \\ Philadelphia, PA 19104, USA \\ bUniversity of Pennsylvania Perelman School of Medicine, Philadelphia, PA 19104, USA \\ 'Department of Psychology and The Neuroscience Program, Temple University, Philadelphia, PA \\ 19122, USA \\ \# These authors contributed equally to this work.
}

\section{Abstract}

Adolescence is a sensitive and critical period in brain development where psychiatric disorders such as anxiety, depression and post-traumatic stress disorder are more likely to emerge following a stressful life event. Females are two times more likely to suffer from psychiatric disorders than males. Patients with these disorders show alterations in orexins (also called hypocretins), important neuropeptides that regulate arousal, wakefulness and the hypothalamic-pituitaryadrenal axis activity. Little is known on the role of orexins in mediating arousal behaviors in male and female rats during adolescence or adulthood. Here, we examine the influence of orexin 1 receptor blockade by SB334867 in open-field behavior in male and female rats during early adolescence (PND 31-33) or adulthood (PND 75-77). Animals were injected with 0 (vehicle), 1 , 10 , or $30 \mathrm{mg} / \mathrm{kg} \mathrm{SB} 334867$ (i.p.). Thirty minutes later, they were placed in an open field, and behavior and neuronal activity (c-Fos) were assessed. In adolescent males, SB334867 significantly increased immobility in the $10 \mathrm{mg} / \mathrm{kg}$ group compared to vehicle. However, this increase in immobility in adolescent males was not observed in adolescent females. In contrast to adolescent males, adult males in the $10 \mathrm{mg} / \mathrm{kg}$ dose group showed the opposite effect on immobility compared to vehicle. These results indicate that $10 \mathrm{mg} / \mathrm{kg}$ dose of SB334867 has opposing effects in adolescent and adult males, but few effects in adolescent and adult females. Differences in functional networks between limbic regions may underlie these effects of orexin receptor blockade that are sex- and age-dependent in rats.

\section{Keywords}

SB334867; orexin receptor; open field; sex differences; adolescence

\footnotetext{
"Correspondence to: S. Bhatnagar, Abramson Research Center, Suite 402B, Children's Hospital of Philadelphia, 3615 Civic Center Boulevard, Philadelphia, PA 19104, USA. bhatnagars@email.chop.edu (S. Bhatnagar).

AUTHOR CONTRIBUTIONS

SRB, DAB, SB designed research; SRB, HN, SL performed research; SRB, HN, DAB, SB analyzed data; SRB, HN, DAB, SB wrote the paper.
} 


\section{INTRODUCTION}

Adolescence is a critical and sensitive period in brain development where stress-related psychiatric disorders (e.g. anxiety, depression, post-traumatic stress disorder and substance abuse) are more likely to emerge (Kessler et al., 2001; Paus et al., 2008). In the developing adolescent brain there are important structural, functional and hormonal changes that occur which contribute to a healthy transition to a mature brain (Buchanan et al., 1992; Spear, 2000; Zhang and Rosenkranz, 2012; Caballero et al., 2016). A traumatic event and/or repeated stressors during this critical developmental period have the potential to disrupt the maturation process, rendering adolescents more vulnerable to develop psychiatric disorders (Compas et al., 1993; Heim and Nemeroff, 2001; Teicher et al., 2003). Adding to the complexity, females are two times more likely to suffer from stress-related psychiatric disorders and show different symptomatology compared to males (Kessler et al., 1993; Olff et al., 2007).

Increasing evidence indicates the importance of orexins in stress-related psychiatric disorders. Orexins (orexin-A and orexin-B, also called hypocretins) are important neuropeptides that regulate arousal, the sleep-wake cycle, feeding behavior and the hypothala mic-pituitary-adrenal axis (HPA axis) (Sakurai et al., 1998; Tsunematsu and Yamanaka, 2012). Orexin neurons in the brain are located within the lateral and posterior hypothalamus (Tsunematsu and Yamanaka, 2012; Grafe et al., 2017a). Orexin-A and B are highly conserved and are structurally similar peptides cleaved from the precursor molecule prepro-orexin, and bind to orexin 1 and 2 receptors which are G-protein-coupled receptors (Sakurai et al., 1998, Tsunematsu and Yamanaka, 2012). Orexin 1 and 2 receptors show different patterns of expression in the brain, suggesting there are specific physiological roles for each receptor (Marcus et al., 2001; Grafe et al., 2017b). Activation of orexin receptors increases arousal and wakefulness whereas orexin receptor antagonists decrease arousal and wakefulness (Sakurai, 2007; Alexandre et al., 2013; Mahler et al., 2014). There are numerous brain regions that contain orexin 1 receptors, including the central and basolateral amygdala (BLA), medial prefrontal cortex, locus coeruleus (LC) and posterior paraventricular nucleus of the thalamus (pPVT) (Marcus et al., 2001; Heydendael et al., 2011). These brain regions are also sensitive to arousal and stress (Kessler et al., 1993; Bhatnagar et al., 2002; Toledo-Rodriguez and Sandi, 2007; Heydendael et al., 2011, 2014; Johnson et al., 2012; Chen et al., 2015; Grafe et al., 2017a). Considering that the orexin system is altered in patients suffering from stress-related psychiatric disorders (Strawn et al., 2010; Johnson et al., 2012; Chen et al., 2015), and that these disorders more often affect females than males, it is likely there are sex differences in the orexin system. Indeed, recent work from our lab demonstrates that orexins mediate the adaptation to repeated restraint stress in a sex-specific manner (Grafe et al., 2017a). However, little is known about sex differences in the orexin system, and it is not known if the orexin system changes across development. Here, we investigated the role of orexins in mediating behaviors related to arousal in males compared to females during adolescence or adulthood using administration of the orexin 1 receptor antagonist SB334867. 


\section{EXPERIMENTAL PROCEDURES}

\section{Animals}

Male and female, adolescent (PND 24) and adult (PND 69) Sprague-Dawley rats (Charles River, Kingston, NY, USA) were single housed at arrival with food and water available ad libitum. The animal room was on a 12:12-h light: dark cycle, with lights turning on at 0615 h. Animals acclimated in the facility for 5 days. The rats were handled and weighed by the experimenter on the two days prior to the experiment and then again on the day of the experiment to determine an accurate vehicle/SB334867 dose. There were four cohorts of experiments that included 176 animals. The first three cohorts took 9 days to complete (3 days for each cohort). Each day there were four open-field arenas used to run 16 animals per experiment day (48 animals per cohort over the 3 days). In the last cohort, 24 animals were included in the experiment (12 animals per day for 2 days). All experiments were conducted between the hours of 8:00 and 13:00. All experimental procedures were carried out according to the National Institutes of Health Guide for the Care and Use of Laboratory Animals and were approved by the Institutional Animal Care and Use Committee at the Children's Hospital of Philadelphia Research Institute.

\section{Drug preparation and administration}

The orexin 1 receptor antagonist, SB334867 (Tocris, Bristol, United Kingdom) was suspended in 10\% $\beta$-cyclodextrin (Sigma) and 7.5\% dimethylsulfoxide (DMSO; Sigma) in a $0.9 \% \mathrm{NaCl}$ (saline) solution. The vehicle was $10 \% \beta$-cyclodextrin and $7.5 \%$ dimethylsulfoxide in a $0.9 \% \mathrm{NaCl}$ (saline) solution. Based on previous behavioral studies (Cason and Aston-Jones, 2013; Rodgers et al., 2013), $0 \mathrm{mg}$ (vehicle), $1 \mathrm{mg}, 10 \mathrm{mg}$ and 30 $\mathrm{mg} / \mathrm{kg}$ doses were selected to examine the effects of orexin 1 receptor blockade on behavior in the open field. The final concentrations for the three doses of SB334867 were $0.5 \mathrm{mg} / \mathrm{mL}$ ( $1 \mathrm{mg} / \mathrm{kg}$ dose), $5 \mathrm{mg} / \mathrm{mL}$ (10 mg/kg dose) and $15 \mathrm{mg} / \mathrm{mL}$ (30 mg/kg dose), with all concentrations having the same injection volume per $\mathrm{kg}$ (animal weight). There were 4 cohorts of experiments, all included vehicle groups. Animals from each sex and age combination (adolescent males, adolescent females, adult males, adult females) were randomly assigned to vehicle, $1 \mathrm{mg} / \mathrm{kg}, 10 \mathrm{mg} / \mathrm{kg}$ or $30 \mathrm{mg} / \mathrm{kg}$ dose groups. Each animal group (adolescent males, adolescent females, adult males, adult females) had the following final number of animals per drug treatment group, vehicle $(n=20), 1 \mathrm{mg} / \mathrm{kg}(n=8), 10$ $\mathrm{mg} / \mathrm{kg}(n=8)$ or $30 \mathrm{mg} / \mathrm{kg}(n=8)$, for a total of 176 animals. On the day of the experiment SB334867 was administered via intraperitoneal (i.p.) injections $30 \mathrm{~min}$ before being placed in the open-field arena.

\section{Open-field behavior analysis}

Animals were transported to an adjacent behavior-testing room (250-300 lux between the floor and $1 \mathrm{~m}$ above the floor) and placed in a corner of the open-field arena $(100 \mathrm{~cm} \times 100$ $\mathrm{cm}$ ) for $30 \mathrm{~min}$ before returning to their home cage. During the behavior test, the experimenter was not in the behavior-testing room. All experiments were recorded with a video camera mounted on a tripod (with camera centered on the arena), about five feet above the open-field arena. After the experiment, videos were downloaded and analyzed on a computer using video analysis software Ethovision XT (Noldus Information Technology, 
Leesburg, VA, USA). The following parameters were selected: high mobility, mobility, immobility, distance traveled, number of center zone entries and time spent in the center zone. Briefly, the software detects animal movements based on the amount of pixel change in the video field. The set parameters for the percentage of pixel change for measuring mobility were determined by the experimenter based on the minimum and maximum amount of pixel change detected in the behavioral videos. The minimum and maximum amount of pixel change of all of the rats was between $0-10 \%$, where $0 \%$ pixel change indicated the animal was immobile and $10 \%$ pixel change was the fastest mobility the rat was capable of. Based on these results, immobility was defined as 0-1\% pixel change, mobility was defined as 1-6\% pixel change and high mobility was defined as $6-100 \%$ pixel change (even though there was no pixel change detected that was higher than 10\%). In general, mobility and high mobility included both trajectory movement (i.e. walking) and stationary movement (i.e. grooming). In the automated analysis the subtraction method of detection was selected; all objects that differed from the background (black open-field arena) were detected. The detection thresholds were set to include the head and body of the animals while excluding the tail. Data were analyzed in 5-min bins. Initial analyses indicated no significant differences in the last $20 \mathrm{~min}$ of the test because animals habituated to the arena. Thus, only data from the first 10 min of open-field exploration are presented here (two 5min bins were grouped) for clarity. In order to examine the total time spent moving (collective time spent mobile), mobility and high mobility behaviors were combined. From the automated analyses, high mobility, time spent mobile (high mobility + mobility), immobility, distance traveled, number of center zone entries and time spent in the center zone were collected for each animal. The latency to enter the center zone was hand coded by an experimenter blind to the experimental groups. Darting behavior was detected by setting a threshold for trajectory movements that reached a velocity of $>23.5 \mathrm{~cm} / \mathrm{s}$, as previously described (Gruene et al., 2015). Darting behavior was quantified from the entire $30 \mathrm{~min}$ of the open-field exploration. The number of darts was averaged from each group.

Behaviors were interpreted as arousal or anxiety-related behaviors. There are some instances when arousal and anxiety behaviors overlap. For example, an anxious animal may display a combination of behaviors indicative of heightened arousal (e.g. fast movements, efforts to escape) and reduced arousal (e.g. immobility) during the same episode of anxious behavior. In our study, we interpreted immobility as arousal and not anxiety, for the following reasons. First, within the drug groups, immobility behavior was not associated with increased in other anxiety-like behaviors (i.e. center zone exploration), as shown in Fig. 2A-C. Second, the posture and position of the animals in the open-field arena were more indicative of resting than what one would observe in an animal bracing itself (i.e. crouching) in a fearful context (Blanchard and Blanchard, 1969; Beck and Fibiger, 1995). Thus, increased immobility was interpreted as less arousal.

\section{c-Fos immunohistochemistry and functional neuronal networks analysis}

Immediately following the 30-min exposure to the open-field behavior, animals were placed back into their home cage for $30 \mathrm{~min}$, and then euthanized via decapitation. Brains were removed and flash-frozen in an isopentane bath and stored at $-80^{\circ} \mathrm{C}$. The brains from animals in the $10 \mathrm{mg} / \mathrm{kg}$ dose group were selected for immunohistochemistry analysis 
because the majority of the meaningful drug effects on open-field behavior were observed in this group. A series of sections (20- $\mu \mathrm{m}$-thick) were collected from the following brain regions ( $\mathrm{mm}$ from bregma): infralimbic and prelimbic regions of the medial prefrontal cortex: -2.70 ; pPVT and BLA: -2.56 to -3.60 ; central amygdala (CeA): -2.56 to -3.14 ; LC: -9.68 to -10.04 (Paxinos and Watson, 1998). Brain sections were fixed in $4 \%$ paraformaldehyde, and immunostained for c-Fos polyclonal primary antibody diluted to 1:1250 (rabbit, sc-52; Santa Cruz Biotechnology, Inc., Santa Cruz, CA, USA) and visualized with diaminobenzidine. Images were quantified using Image J (NIH, USA, http:// imagej.nih.gov/ij/) by an experimenter blind to the experimental groups. The cell density was quantified by dividing the number of c-Fos-positive cells by the area of the brain region according to bregma level. The area was determined using the free-form drawing tool in Image $\mathrm{J}$ to trace the nuclei of each structure. For each animal, $2-3$ sections were quantified per brain region.

\section{Statistical analysis}

Statistical analysis was performed using Prism 6 software (GraphPad, La Jolla, CA, USA). Behavior and c-Fos cell density were analyzed using a two-way analysis of variance (ANOVA) test comparing sex $\times$ drug dose in adolescents or in adults. Following significant interactions, data were analyzed using Tukey's post hoc tests. Differences in functional networks between brain regions were quantified by correlating c-Fos expression between interconnected brain regions and then the correlations were statistically compared between drug- and vehicle-treated groups, as previously described (Maras et al., 2014; Dwyer and Leslie, 2016; Wiersielis et al., 2016). All brain regions that share anatomical connections were correlated (Pearson's product moment correlations) and compared using Fisher's $r$ to $Z$ transformations. Fisher's $z$-tests were performed to assess differences between drug- and vehicle-treated groups.

\section{RESULTS}

\section{Open-field behavior}

High mobility.-In adolescent males and females, there were no significant effects of drug or sex on the duration of high mobility behavior during open-field exploration (Fig. 1A). In adults, overall, females displayed longer durations of high mobility compared to males (Fig. $1 \mathrm{~A}$; significant main effect of sex: $F(1,80)=18.17, p<0.0001)$. There was also a significant interaction $(F(3,80)=5.52, p<0.01)$. Post hoc results indicated vehicle- and $1 \mathrm{mg} / \mathrm{kg}$ treated adult males spent less time highly mobile compared to vehicle- and $1 \mathrm{mg} / \mathrm{kg}$-treated adult females, respectively $(p<0.001)$. Although not significant, adult males in the 10 $\mathrm{mg} / \mathrm{kg}$ dose group spent more time highly mobile compared to vehicle. In adult females, the $10 \mathrm{mg} / \mathrm{kg}$ dose significantly reduced the time spent highly mobile compared to vehicle ( $p<$ $0.05)$. Thus, orexin 1 receptor blockade $(10 \mathrm{mg} / \mathrm{kg})$ elevated high mobility in adult males but reduced high mobility in females compared to their respective vehicle groups and no significant effects were observed among adolescents.

Collective time spent mobile.-In adolescents, there was a significant main effect of sex on the collective time spent mobile $(F(1,77)=5.98, p<0.05$; Fig. 1B). Overall, 
adolescent females spent less time mobile compared to adolescent males, regardless of the treatment group. There was a significant interaction effect $(F(3,77)=4.64, p<0.01)$ within the adolescent groups, however, no significant post hoc results were observed. In adults, there was a significant main effect of $\operatorname{sex}(F(1,80)=10.62, p<0.01$; Fig. 1B) but in contrast to adolescents, adult females spent more time mobile overall than males. There was a significant interaction effect $(F(3,80)=4.57, p<0.01)$. Post hoc results indicated that adult males in the $10 \mathrm{mg} / \mathrm{kg}$ group spent more time mobile than adult males in the $1 \mathrm{mg} / \mathrm{kg}$ group. Vehicle-treated males spent less time mobile compared to vehicle-treated females, and similar effects were observed in the $1 \mathrm{mg} / \mathrm{kg}$-treated groups. No differences between the female adults were observed. Thus, the collective time spent mobile during open-field exploration does not seem to be sensitive to orexin 1 receptor blockade in adolescent or adult females.

Immobility.-In adolescents, there was a significant main effect of $\operatorname{sex}(F(1,77)=4.88, p<$ 0.05 ; Fig. 1C) and a significant interaction effect $(F(3,77)=5.20, p<0.01)$ on the time spent immobile. Adolescent females spent more time immobile overall compared to adolescent males, regardless of orexin 1 receptor antagonist. Within the adolescent males, post hoc results demonstrated that the $10 \mathrm{mg} / \mathrm{kg}$-treated group had significantly higher immobility than the vehicle and $1 \mathrm{mg} / \mathrm{kg}$ group. These data suggest that immobility behavior is sensitive to orexin 1 receptor antagonist in adolescent males, but not in adolescent females. In adults, overall, males spent more time immobile compared to females (significant sex effect; $F(1,80)=11.31, p<0.01 ;$ Fig. 1C). There was a significant interaction effect $(F(3,80)=$ $3.89, p<0.05)$ in adults. Post hoc analyses revealed that $10 \mathrm{mg} / \mathrm{kg}$-treated adult males spent less time immobile compared to the $1 \mathrm{mg} / \mathrm{kg}$ dose group. Collectively, orexin 1 receptor blockade regulates immobility differently in adolescent compared to adult males but has no effects in adult females.

Distance traveled.-The distance traveled during open-field exploration is another behavior measure that may be sensitive to the state of arousal in animals. No significant effects were observed in adolescents, indicating that adolescent males and females displayed similar distance traveled, regardless of their treatment group (Fig. 1D). In adults, there were trends for significant main effects of sex and dose (sex: $F(1,80)=3.68, p=0.059$; drug dose: $F(3,80)=2.26, p=0.088$; Fig. 1D). Furthermore, there was a significant interaction $(F(3,80)$ $=3.32, p<0.05)$. Post hoc tests revealed $1 \mathrm{mg} / \mathrm{kg}$-treated adult males traveled less distance than $1 \mathrm{mg} / \mathrm{kg}$-treated adult females $(p<0.05)$. Overall, these data suggest that the $1 \mathrm{mg} / \mathrm{kg}$ dose of SB334867 altered distance traveled in adults, but not in adolescents.

Center zone exploration.-Exploration into the center zone of the open-field arena is thought to be an indication of the animal's level of anxiety (Stefanski et al., 1992; Sestakova et al., 2013). There were no significant effects in the number of center zone entries (Fig. 2A) or the total time spent exploring in the center zone (Fig. 2B) in either adolescents or adults. The latency to enter the center zone was also measured (Fig. 2C). There were significant sex effects in both adolescents $(F(1,76)=5.14, p<0.05)$ and adults $(F(1,76)=6.66, p<0.05)$. Overall, adolescent females exhibited longer latencies to enter the center zone compared to 
adolescent males but adult females exhibited shorter latencies compared to adult males. However, no significant effects of SB334867 were observed in exploration of center zones.

Darting behavior.-Darting behavior is an adaptive/escape-like response to novel/fearful environment that is expressed in a sex-dependent manner (Gruene et al., 2015). There were no significant effects of sex or drug $(10 \mathrm{mg} / \mathrm{kg})$ on the number of darts in adolescent males and females (Fig. 2D). In adults, there was a significant main effect of $\operatorname{sex}(F(1,23)=12.32$, $p=0.0019$ ) (Fig. 2D). Overall, adult females had a higher number of darts compared to adult males. There was a trend for significant main effect of drug $(F(1,23)=3.92, p=$ 0.060). These data suggest that adult females, not adult males, respond to the novel environment of the open field by darting.

\section{Neural activity}

The behavioral results described above indicated most effects occurred with the $10 \mathrm{mg} / \mathrm{kg}$ dose of SB334867. Therefore, for assessment of neuronal activity related to open-field exploration, we focused on rats in this dose group.

Central amygdala.-In adolescents, there was a significant main effect of drug on the density of c-Fos-stained neurons $(F(1,68)=5.653, p<0.05$; Fig. 3A). Adolescent males treated with $10 \mathrm{mg} / \mathrm{kg}$ of orexin 1 receptor antagonist had increased density of c-Fos-stained neurons in the CeA compared to vehicle $(p<0.05)$. In adults, there was a significant drug effect $(F(1,81)=13.03, p<0.001)$ with the orexin 1 receptor antagonist increasing density of c-Fos-stained neurons compared to vehicle, regardless of sex (Fig. 3A).

Posterior paraventricular nucleus of the thalamus.-In adolescents, no significant effect of sex or drug was observed in the pPVT (Fig. 3B). In adults, there were no main effects of drug or sex, however, there was a significant interaction $(F(1,26)=9.79, p<0.01)$. Post hoc results demonstrated a trend where vehicle-treated adult males had greater density of neuronal c-Fos compared to drug-treated adult males and vehicle-treated adult females ( $p$ $=0.073-0.082$ ).

Medial prefrontal cortex.-In the prelimbic cortex (PL) (Fig. 4A), there were no significant effects in adolescent rats. In adults, there was a significant interaction, where vehicle-treated females had higher density than $10 \mathrm{mg} / \mathrm{kg}$-treated females and vehicletreated males $(F(1,42)=6.99, p<0.05)$. In the infralimbic cortex (IL) (Fig. 4B), there was a significant main effect of drug $(F(1,46)=6.42, p<0.05)$ in adolescents, with decreased density of c-Fos-stained neurons in the $10 \mathrm{mg} / \mathrm{kg}$ dose groups compared to vehicles. There were no significant effects in adults.

Locus coeruleus.-There were no significant effects in adolescents (Fig. 4C). In adults, there was a significant drug $\mathrm{X}$ sex interaction $(F(1,41)=4.72, p<0.05)$. Post hoc tests indicated a trend in adult males of reduced c-Fos density $(p=0.07)$ by the drug compared to vehicle.

Basolateral amygdala.-In adolescents, there were no significant effects of sex or drug on density of c-Fos-immunoreactive cells in the BLA (Fig. 4D). There was a significant sex 
effect in adults $(F(1,31)=4.23, p<0.05)$ with females exhibiting higher $\mathrm{c}$-Fos densities than males. No other effects of sex or drug were observed.

\section{Correlations between neural activity (c-Fos immunoreactivity) and open-field behaviors}

Neural activity (c-Fos) in brain regions known to be involved in arousal- and anxiety-related behaviors in the open field were correlated in both vehicle- and drug-treated groups. There were no significant correlations between center zone exploration (Number of center zone entries, latency to enter the center zone, time spent in center zone) and BLA neural activity, immobility and CeA neural activity, and time spent mobile and LC neural activity.

\section{Networks activated (c-Fos immunoreactivity) by orexin 1 receptor antagonist}

Neuronal activity (c-Fos) in brain regions with known anatomical connections were correlated within each age/sex group, in the $10 \mathrm{mg} / \mathrm{kg}$ orexin 1 receptor antagonist treatment group (Table 1). For example, in adolescent males treated with $10 \mathrm{mg} / \mathrm{kg}$ orexin 1 receptor antagonist (SB334867), neuronal activity (c-Fos) in the CeA correlated with neuronal activity in the BLA (Table 1). However, vehicle-treated adolescent males did not have a significant correlation between neuronal activity in the central and BLA (Table 1). Next, these correlations were compared (vehicle vs $10 \mathrm{mg} / \mathrm{kg}$ orexin 1 receptor antagonist, for each age and sex group) using Fisher's $z$-tests to identify activation of interconnected brain regions (Table 2). In adolescent females, orexin 1 receptor antagonist altered functional networks between the basolateral and CeA. Adult females showed altered functional networks between the pPVT and the IL. There was a trend for altered functional networks between the pPVT and the PL in adult females. In adult males, there was a trend for differences in functional networks between the IL and the BLA.

\section{DISCUSSION}

The goals of this study were (1) to examine the role of orexins in mediating anxiety- and arousal-related behaviors in male compared to female rats and (2) determine how this role changes from adolescence to adulthood and (3) to identify neural pathways that underlie this role of orexins. To accomplish these goals, the effects of orexin 1 receptor antagonism on open-field exploration behavior were examined in adolescent and adult, male and female rats. Overall, orexin 1 receptor antagonism had the greatest effects on arousal-related behaviors (mobility/immobility in the open field), and little to no effect on anxiety-related behaviors (center zone exploration in the open field). Furthermore, orexin 1 receptor antagonism modulated arousal-related behavior in males more than in females, regardless of age. The most salient findings were the effects on arousal-related behaviors observed specifically in the $10 \mathrm{mg} / \mathrm{kg}$ dose group. Collectively, these findings indicated that orexin 1 receptor antagonism increased arousal-related behaviors in adult males but decreased arousal-related behaviors in adolescent males while having fewer effects in females.

Adult males treated with the $10 \mathrm{mg} / \mathrm{kg}$ dose showed a modest increase their collective time spent mobile (mobility includes both high mobility, such as fast movements, and total time spent mobile) and a modest reduction in immobility, suggesting increases in indices of overall arousal whereas the opposite was observed in adolescent male rats treated with this 
dose of antagonist. In adults, the commonly understood role of orexins as activators of arousal would lead to the prediction that orexin receptor blockade will reduce arousal. However, there was a modest increase in arousal in adults and a significant decrease in arousal in adolescents. It could be that the open field produces different levels of arousal in adult compared to adolescent rats. For example, the literature suggests that the effects of orexin receptor blockade on immobility depends on the level of stress of the animal or intensity of the arousal state (Soya et al., 2013; Chen et al., 2014; Wang et al., 2017). Reduced immobility (i.e. increased arousal) in the context of shock is observed after orexin 1 receptor blockade but not in non-shocked rats (Chen et al., 2014). This could suggest that the open field elicits more arousal or a more intense experience for adult males compared to adolescent males and this is leading to reduced arousal in the adolescents but increased arousal in adults. Although we do not directly measure physiological endpoints of arousal, we referred to changes in immobility as changes in arousal based on our observations of the animals in the videos. Based on the posture of the animals during episodes of immobility (they display no signs of crouching), we believe they are not moving (which would indicate reduced arousal), as opposed to freezing (which would indicate increased arousal). It is also possible that the reduced immobility in adult males reflects increased anxiety-related behavior, however this is not borne out by other common measures of anxiety-related behaviors such as time in center zone. Thus, the unexpected effect of orexin 1 receptor antagonist on immobility behavior observed in adult males may be a reflection of a heightened stress level during the behavioral task.

Of the few effects observed in females, adult females treated with the $10 \mathrm{mg} / \mathrm{kg}$ orexin 1 receptor antagonist dose displayed shorter duration of high-mobility behavior than vehicletreated adult females, consistent with the idea that orexin receptor blockade should reduce indices of arousal. It is possible adult females have a different way of adapting/coping to novel environments than what we observed in adult males (Gruene et al., 2015). To address this possibility, darting behavior was examined. Adult females had a higher dart frequency than adult males, and although not significant, orexin 1 receptor antagonist reduced the frequency of darts in adult females. This is consistent with the effect of $10 \mathrm{mg} / \mathrm{kg}$ orexin 1 receptor antagonist dose on high mobility in adult females. This sex difference in mobility and darting behavior could also be because of differences in orexin 1 receptor distribution in regions innervated by orexin neurons that are relevant for mediating arousal-related behaviors in the open field in males compared to females. Furthermore, we used randomly cycling females, thus there may be patterns of behavioral effects in females that are differentially regulated across the cycle. Our previous work has demonstrated higher preproorexin mRNA and release in cerebral spinal fluid in non-stressed female compared to male rats (Grafe et al., 2017a). Therefore, the blockade of these high levels of orexins in adult females may be expected to reduce mobility and arousal, as shown in the high-mobility behavior. However, besides the reduction in high mobility in adult females, there were no significant effects of orexin 1 receptor blockade on open-field behaviors in adolescent and adult females. The behavioral effects of orexin 1 receptor blockade in females may be more dependent on the animal's stress level. It is possible that anxiety-related open-field behaviors are not sensitive to orexin 1 receptor blockade, even in the presence of higher orexin levels basally (as observed in females, (Grafe et al., 2017a) because the open field is a mild 
stressor (as opposed to repeated restraint stress, (Grafe et al., 2017a). Similarly, with lower orexin levels basally in adult males, the effects of antagonism may also be more dependent on the stress state of the animal and produce increases in arousal, as shown in all mobility behaviors. Orexin 1 receptor expression in adolescent and adult, male and female rats is largely unknown. It is possible there are age-, sex- and stress-dependent differences in orexin 1 receptor expression and trafficking. These possibilities will be examined in future studies.

The Orexin 1 receptor antagonist ( $10 \mathrm{mg} / \mathrm{kg}$ dose) modulated neuronal activity (c-Fos immunoreactivity) in the prelimbic and infralimbic regions of the medial prefrontal cortex and in the pPVT. We assessed neuronal activity changes produced by the $10 \mathrm{mg} / \mathrm{kg}$ dose of antagonist because the major and most meaningful significant effects across age and across sex were observed with this dose. The behavioral effects of the $1 \mathrm{mg} / \mathrm{kg}$ dose are primarily in comparison with other doses and not compared to the vehicle controls. In contrast, the 10 $\mathrm{mg} / \mathrm{kg}$ dose effects are primarily vs. the vehicle controls. This is important because vehicle injections are often associated with different behaviors across age or between the sexes. Thus, when the $1 \mathrm{mg} / \mathrm{kg}$ dose effect is significant compared to the same dose across sex or across age, that may only be due to the fact that the vehicles also are different, an indication that the entire group is responding at a different level. In contrast, in most cases, the 10 $\mathrm{mg} / \mathrm{kg}$ induced a different direction of effect when compared to vehicle across sexes or ages. For example, in immobility, in adolescent males, the $10 \mathrm{mg} / \mathrm{kg}$ induces increases in immobility compared to vehicle but this same dose produces decreases in adults compared to vehicle. In both ages, the $1 \mathrm{mg} / \mathrm{kg}$ dose, while different from the $10 \mathrm{mg} / \mathrm{kg}$ dose, is not different than vehicles. Thus, we concluded that the $10 \mathrm{mg} / \mathrm{kg}$ dose produced the most meaningful effects across age and across sex and examined the neural activity patterns in response to only this dose of antagonist. Nonetheless, it is possible that some effects of the 1 $\mathrm{mg} / \mathrm{kg}$ dose on neural activity may have been informative for the interpretations of the behavioral effects of either dose. As such, this is a limitation of the current study.

Orexin 1 receptor blockade $(10 \mathrm{mg} / \mathrm{kg}$ dose $)$ in the $\mathrm{mPFC}$ of both male and female adolescent groups reduced neuronal activity in the IL. However, the PL in adults that received orexin 1 receptor antagonist had reduced neuronal activity in females, but not in males. Orexin 1 receptor expression is high in the pPVT (Marcus et al., 2001) and adult males and females had a sex-specific effect of orexin 1 receptor blockade on c-Fos immunoreactivity, with males showing a trend of decreased neuronal activity compared to vehicles and females showing the opposite trend. There were no effects of orexin 1 receptor blockade on c-Fos immunoreactivity in the pPVT in adolescents. Overall, this suggests that in the pPVT, either endogenous orexins or orexin 1 receptor expression (or a combination of both) change across development.

One limitation of our study was the use of single housing of the rats prior to drug injection and behavioral testing. For example, Varlinskaya and Spear have shown that adolescent rats were more sensitive to the effects of single housing compared to adult rats (Varlinskaya and Spear. 2008). Weiss et al. have shown that post-weaning social isolation affects behavioral and hormonal hyper-reactivity to stressful situations in males, but not in females (Weiss et al., 2004). Lukkes et al. have discussed differences in critical periods of social isolation for male and female rats in terms of increased anxiety-related behavior. Their studies suggest 
that social isolation rearing of male rats must occur during a critical window to have longlasting anxiety-related effects while a critical window may not exist for female rats (Lukkes et al., 2009). One of our previous studies suggest that social isolation during adolescence impacts the HPA response to restraint in females but not in males at the end of adolescence (Weintraub et al., 2010). These and other potential effects of single housing may have impacted the behavioral effects of orexin receptor blockade differentially in adolescent compared to adult rats.

Many of the brain regions analyzed for neuronal activity are interconnected neuronal circuits implicated in psychiatric disorders (Kessler et al., 1993; Toledo-Rodriguez and Sandi, 2007; Heydendael et al., 2011, 2014; Johnson et al., 2012; Chen et al., 2015; Wood and Bhatnagar, 2015; Grafe et al., 2017a). To determine the effects of orexin 1 receptor antagonist on these interconnected neural circuits, neuronal activity (c-Fos immunoreactivity) correlations from interconnected brain regions were statistically compared to examine whether orexin 1 receptor antagonist administration altered functional networks, for each sex and age group. This type of analysis is hypothesis generating, and has the potential to show which orexin 1 receptor antagonist activated brain regions may work together in functional neuronal networks, in an age- and/or sex-dependent manner. The orexin 1 receptor antagonist altered the functional networks between the pPVT and IL, and the pPVT and PL (trend) in adult females. In adolescent females, the orexin 1 receptor antagonist altered the functional networks between the BLA and CeA. This suggests that the similar behavioral effects produced by orexin 1 receptor blockade in adolescent compared to adult females may occur through different circuits with a predominance of pPVT-related circuits in adult females. In adult males, the functional networks between the IL and the BLA were altered (trend) by orexin 1 receptor antagonist but no significant changes in networks were observed in adolescent males. This suggest that the different behavioral effects produced by orexin receptor blockade in adolescent compared to adult males again is occurring through different circuits, with less of a role of IL and BLA networks in adolescence. These results can be pursued in future studies but they do not rule out possible roles for other relevant regions that were not examined here.

\section{ACKNOWLEDGMENTS}

This work was supported by R01MH093981 to SB. The content is the sole responsibility of the authors and does not necessarily represent the official views of the National Institute of Mental Health. We gratefully acknowledge Darrell Eacret, Nathaniel Sotuyo and Joey Benjamini for their help in acquiring open-field behavior and behavior analysis in Ethovision XT - Noldus software.

\section{Abbreviations:}

$\begin{array}{ll}\text { BLA } & \text { basolateral amygdala } \\ \text { CeA } & \text { central amygdala } \\ \text { i.p } & \text { intraperitoneal } \\ \text { IL } & \text { infralimbic cortex } \\ \text { LC } & \text { locus coeruleus }\end{array}$



PL prelimbic cortex
PND postnatal day
pPVT posterior paraventricular nucleus of the thalamus
SEM standard error of the mean

\section{REFERENCES}

Alexandre C, Andermann ML, Scammell TE (2013) Control of arousal by the orexin neurons. Curr Opin Neurobiol 23:752-759. [PubMed: 23683477]

Beck CH, Fibiger HC (1995) Conditioned fear-induced changes in behavior and in the expression of the immediate early gene c-fos: with and without diazepam pretreatment. J Neurosci 15:709-720. [PubMed: 7823174]

Bhatnagar S, Huber R, Nowak N, Trotter P (2002) Lesions of the posterior paraventricular thalamus block habituation of hypothalamic-pituitary-adrenal responses to repeated restraint. $\mathrm{J}$ Neuroendocrinol 14:403-410. [PubMed: 12000546]

Blanchard RJ, Blanchard DC (1969) Crouching as an index of fear. J Comp Physiol Psychol 67:370375. [PubMed: 5787388]

Buchanan CM, Eccles JS, Becker JB (1992) Are adolescents the victims of raging hormones: evidence for activational effects of hormones on moods and behavior at adolescence. Psychol Bull 111:62107. [PubMed: 1539089]

Caballero A, Granberg R, Tseng KY (2016) Mechanisms contributing to prefrontal cortex maturation during adolescence. Neurosci Biobehav Rev 70:4-12. [PubMed: 27235076]

Cason AM, Aston-Jones G (2013) Attenuation of saccharin-seeking in rats by orexin/hypocretin receptor 1 antagonist. Psychopharmacology 228:499-507. [PubMed: 23494235]

Chen Q, de Lecea L, Hu Z, Gao D (2015) The hypocretin/orexin system: an increasingly important role in neuropsychiatry. Med Res Rev 35:152-197. [PubMed: 25044006]

Chen X, Wang H, Lin Z, Li S, Li Y, Bergen HT, Vrontakis ME, Kirouac GJ (2014) Orexins (hypocretins) contribute to fear and avoidance in rats exposed to a single episode of footshocks. Brain Struct Funct 219:2103-2118. [PubMed: 23955372]

Compas BE, Orosan PG, Grant KE (1993) Adolescent stress and coping: implications for psychopathology during adolescence. J Adolesc 16:331-349. [PubMed: 8282901]

Dwyer JB, Leslie FM (2016) Adolescent maturation of dopamine D1 and D2 receptor function and interactions in rodents. PLoS ONE 11:e0146966. [PubMed: 26784516]

Grafe LA, Cornfeld A, Luz S, Valentino R, Bhatnagar S (2017a) Orexins mediate sex differences in the stress response and in cognitive flexibility. Biol Psychiatry 81:683-692. [PubMed: 27955897]

Grafe LA, Eacret D, Luz S, Gotter AL, Renger JJ, Winrow CJ, Bhatnagar S (2017b) Orexin 2 receptor regulation of the hypothalamic-pituitary-adrenal (HPA) response to acute and repeated stress. Neuroscience 348:313-323. [PubMed: 28257896]

Gruene TM, Flick K, Stefano A, Shea SD, Shansky RM (2015) Sexually divergent expression of active and passive conditioned fear responses in rats. eLife 4.

Heim C, Nemeroff CB (2001) The role of childhood trauma in the neurobiology of mood and anxiety disorders: preclinical and clinical studies. Biol Psychiatry 49:1023-1039. [PubMed: 11430844]

Heydendael W, Sengupta A, Beck S, Bhatnagar S (2014) Optogenetic examination identifies a contextspecific role for orexins/hypocretins in anxiety-related behavior. Physiol Behav 130:182-190. [PubMed: 24140988]

Heydendael W, Sharma K, Iyer V, Luz S, Piel D, Beck S, Bhatnagar S (2011) Orexins/hypocretins act in the posterior paraventricular thalamic nucleus during repeated stress to regulate facilitation to novel stress. Endocrinology 152:4738-4752. [PubMed: 21971160]

Johnson PL, Molosh A, Fitz SD, Truitt WA, Shekhar A (2012) Orexin, stress, and anxiety/panic states. Prog Brain Res 198:133-161. [PubMed: 22813973] 
Kessler RC, Avenevoli S, Ries Merikangas K (2001) Mood disorders in children and adolescents: an epidemiologic perspective. Biol Psychiatry 49:1002-1014. [PubMed: 11430842]

Kessler RC, McGonagle KA, Swartz M, Blazer DG, Nelson CB (1993) Sex and depression in the National Comorbidity Survey. I: Lifetime prevalence, chronicity and recurrence. J Affect Disord 29:85-96. [PubMed: 8300981]

Lukkes JL, Watt MJ, Lowry CA, Forster GL (2009) Consequences of post-weaning social isolation on anxiety behavior and related neural circuits in rodents. Front Behav Neurosci 20(3):18.

Mahler SV, Moorman DE, Smith RJ, James MH, Aston-Jones G (2014) Motivational activation: a unifying hypothesis of orexin/hypocretin function. Nat Neurosci 17:1298-1303. [PubMed: 25254979]

Maras PM, Molet J, Chen Y, Rice C, Ji SG, Solodkin A, Baram TZ (2014) Preferential loss of dorsalhippocampus synapses underlies memory impairments provoked by short, multi-modal stress. Mol Psychiatry 19:745. [PubMed: 24969262]

Marcus JN, Aschkenasi CJ, Lee CE, Chemelli RM, Saper CB, Yanagisawa M, Elmquist JK (2001) Differential expression of orexin receptors 1 and 2 in the rat brain. J Comp Neurol 435:6-25. [PubMed: 11370008]

Olff M, Langeland W, Draijer N, Gersons BP (2007) Gender differences in posttraumatic stress disorder. Psychol Bull 133:183-204. [PubMed: 17338596]

Paus T, Keshavan M, Giedd JN (2008) Why do many psychiatric disorders emerge during adolescence? Nat Rev Neurosci 9:947-957. [PubMed: 19002191]

Paxinos G, Watson C (1998) The rat brain in stereotaxic coordinates. North Ryde: Academic Press.

Rodgers RJ, Wright FL, Snow NF, Taylor LJ (2013) Orexin-1 receptor antagonism fails to reduce anxiety-like behaviour in either plus-maze-naive or plus-maze-experienced mice. Behav Brain Res 243:213-219. [PubMed: 23333844]

Sakurai T (2007) The neural circuit of orexin (hypocretin): maintaining sleep and wakefulness. Nat Rev Neurosci 8:171-181. [PubMed: 17299454]

Sakurai T, Amemiya A, Ishii M, Matsuzaki I, Chemelli RM, Tanaka H, Williams SC, Richarson JA, Kozlowski GP, Wilson S, Arch JR, Buckingham RE, Haynes AC, Carr SA, Annan RS, McNulty DE, Liu WS, Terrett JA, Elshourbagy NA, Bergsma DJ, Yanagisawa M (1998) Orexins and orexin receptors: a family of hypothalamic neuropeptides and $\mathrm{G}$ protein-coupled receptors that regulate feeding behavior. Cell 92:573-585. [PubMed: 9491897]

Sestakova N, Puzserova A, Kluknavsky M, Bernatova I (2013) Determination of motor activity and anxiety-related behaviour in rodents: methodological aspects and role of nitric oxide. Interdiscip Toxicol 6:126-135. [PubMed: 24678249]

Soya S, Shoji H, Hasegawa E, Hondo M, Miyakawa T, Yanagisawa M, Mieda M, Sakurai T (2013) Orexin receptor-1 in the locus coeruleus plays an important role in cue-dependent fear memory consolidation. J Neurosci 33:14549-14557. [PubMed: 24005305]

Spear LP (2000) The adolescent brain and age-related behavioral manifestations. Neurosci Biobehav Rev 24:417-463. [PubMed: 10817843]

Stefanski R, Palejko W, Kostowski W, Plaznik A (1992) The comparison of benzodiazepine derivatives and serotonergic agonists and antagonists in two animal models of anxiety. Neuropharmacology 31:1251-1258. [PubMed: 1470301]

Strawn JR, Pyne-Geithman GJ, Ekhator NN, Horn PS, Uhde TW, Shutter LA, Baker DG, Geracioti $\mathrm{TD}, \mathrm{Jr}$ (2010) Low cerebrospinal fluid and plasma orexin-A (hypocretin-1) concentrations in combat-related posttraumatic stress disorder. Psychoneuroendocrinology 35:1001-1007. [PubMed: 20116928]

Teicher MH, Andersen SL, Polcari A, Anderson CM, Navalta CP, Kim DM (2003) The neurobiological consequences of early stress and childhood maltreatment. Neurosci Biobehav Rev 27:33-44. [PubMed: 12732221]

Toledo-Rodriguez M, Sandi C (2007) Stress before puberty exerts a sex- and age-related impact on auditory and contextual fear conditioning in the rat. Neural Plasticity 2007:71203. [PubMed: 17671613]

Tsunematsu T, Yamanaka A (2012) The role of orexin/hypocretin in the central nervous system and peripheral tissues. Vitam Horm 89:19-33. [PubMed: 22640606] 
Varlinskaya EI, Spear LP (2008) Social interactions in adolescent and adult Sprague-Dawley rats: impact of social deprivation and test context familiarity. Behav Brain Res 188(2):398-405. [PubMed: 18242726]

Wang H, Li S, Kirouac GJ (2017) Role of the orexin (hypocretin) system in contextual fear conditioning in rats. Behav Brain Res 316:47-53. [PubMed: 27575948]

Weintraub A, Singaravelu J, Bhatnagar S (2010) Enduring and sex-specific effects of adolescent social isolation in rats on adult stress reactivity. Brain Res 9(1343):83-92.

Weiss IC, Pryce CR, Jongen-Rêlo AL, Nanz-Bahr NI, Feldon J (2004) Effect of social isolation on stress related behavioural and neuroendocrine state in the rat. Behav Brain Res 152 (2):279-295. [PubMed: 15196796]

Wiersielis KR, Wicks B, Simko H, Cohen SR, Khantsis S, Baksh N, Waxler DE, Bangasser DA (2016) Sex differences in corticotropin releasing factor-evoked behavior and activated networks. Psychoneuroendocrinology 73:204-216. [PubMed: 27521739]

Wood SK, Bhatnagar S (2015) Resilience to the effects of social stress: evidence from clinical and preclinical studies on the role of coping strategies. Neurobiol Stress:164-173. [PubMed: 25580450]

Zhang W, Rosenkranz JA (2012) Repeated restraint stress increases basolateral amygdala neuronal activity in an age-dependent manner. Neuroscience 226:459-474. [PubMed: 22986163] 
Adolescents

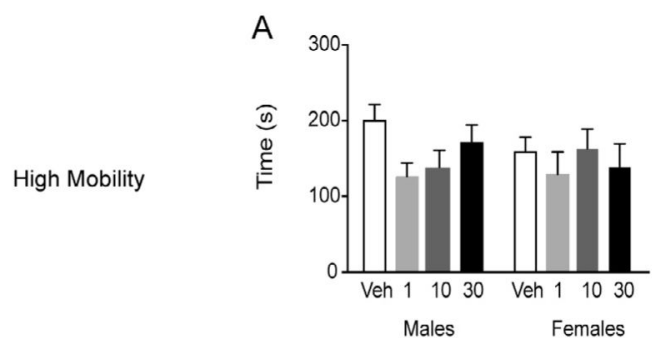

B

Collective Time Spent Mobile

Distance Traveled

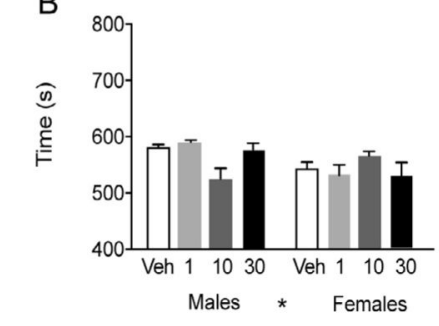

C
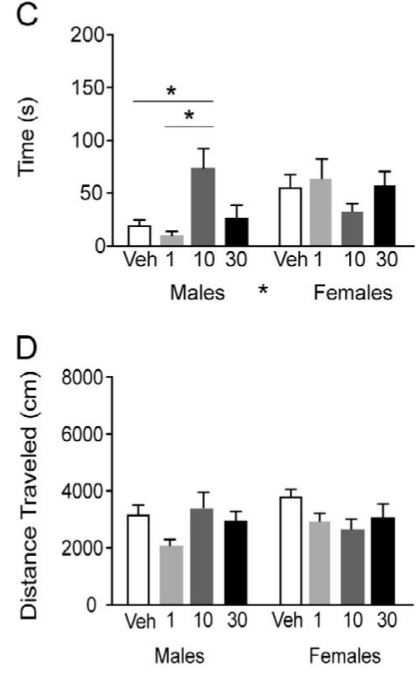
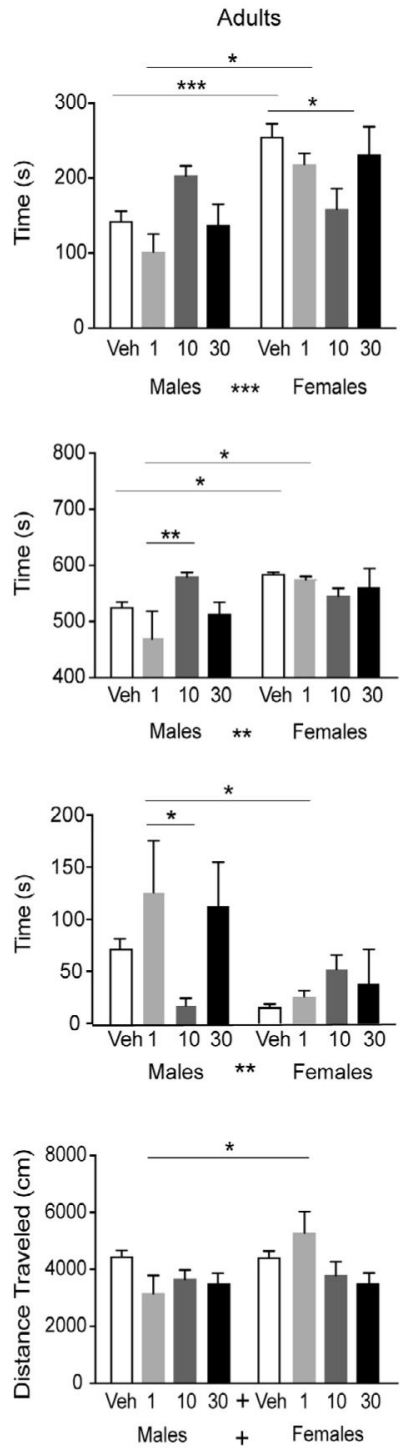

Fig. 1.

Effects of orexin 1 receptor antagonist on arousal-related open-field behaviors in male and female adolescent or adult rats. Animals were injected with vehicle or SB334867 (1, 10 or $30 \mathrm{mg} / \mathrm{kg}$ i.p.) $30 \mathrm{~min}$ prior to being placed in an open-field arena for $30 \mathrm{~min}$. Adolescents are shown in the left column, adults in the right column. High mobility (A), collective time spent mobile (B), immobility (C), and distance traveled (D) for the first 10 min are shown in vehicle- and SB334867-treated groups in adolescent and adult rats. Data are represented as average \pm SEM. Significant main effects of drug or sex are indicated by $*$ and trends are indicated by + between drug and sex groups on the $\mathrm{x}$-axis. Following a significant interaction, significant post hoc tests are indicated by bars and * above the bars on the graphs. Significant differences are represented as follows: $* p<0.05$, $* * p<0.01$, and $* * * p<$ 0.001 . 

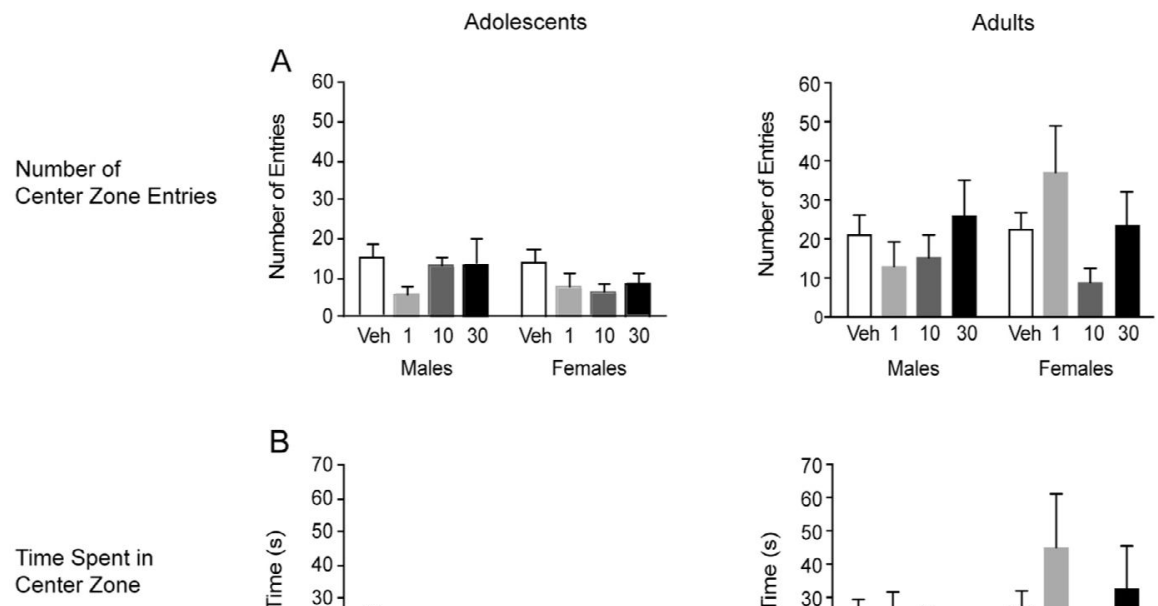

B
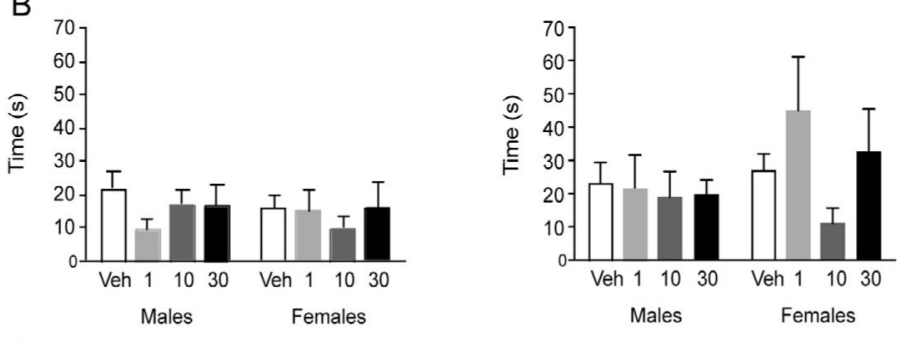

$\mathrm{C}_{1000}$
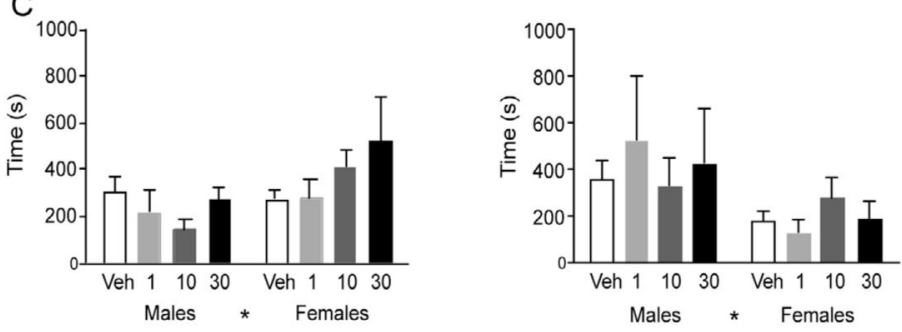

Latency to Enter Center Zone

D
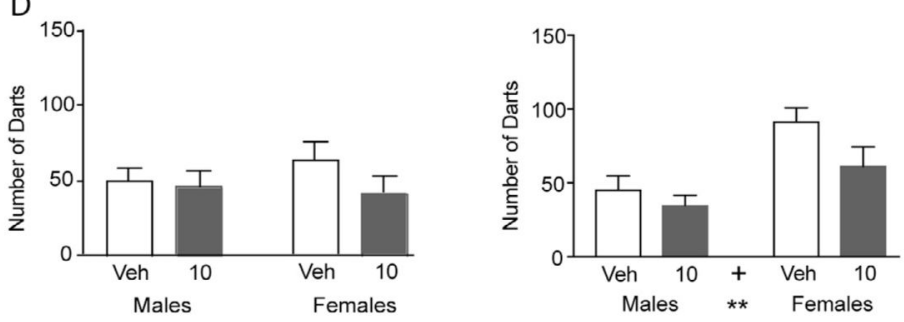

Fig. 2.

Effects of orexin 1 receptor antagonist on anxiety-related open-field behaviors and darting behavior in adolescent and adult rats. Animals were injected with vehicle or SB334867 (1, 10 , or $30 \mathrm{mg} / \mathrm{kg}$ i.p.) $30 \mathrm{~min}$ prior to being placed in an open-field arena for $30 \mathrm{~min}$. Adolescent data are shown in the left column, adult data in the right column. Number of Center Zone Entries (A), Time Spent in Center Zone (B), Latency to Enter Center Zone (C), and the Number of Darts (D) in vehicle- and SB334867-treated groups in adolescent and adult rats were analyzed and represented as average \pm SEM. Significant main effect of sex is indicated by $*$ between sex groups on the $\mathrm{x}$-axis. Significant differences are represented as: $* p<0.05$. 
Central Amygdala
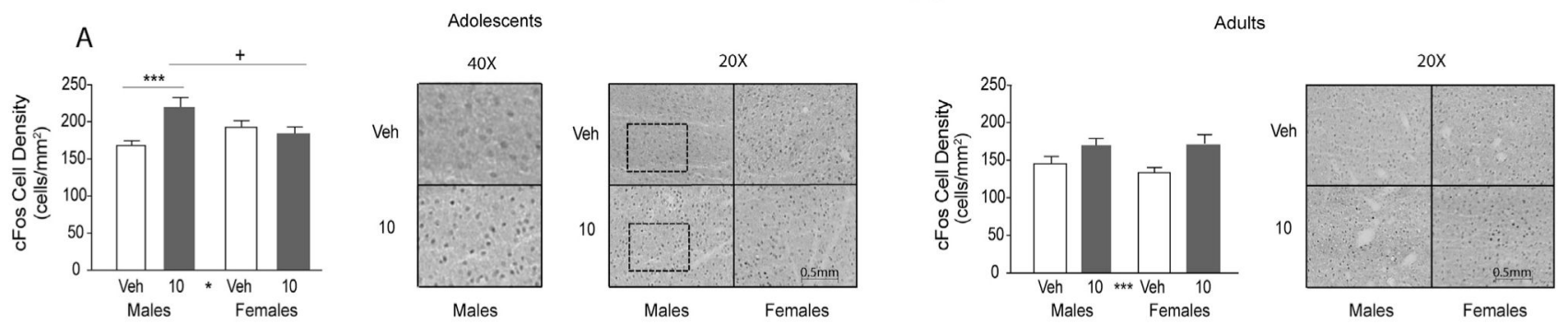

\section{Posterior Paraventricular Nucleus of the Thalamus}
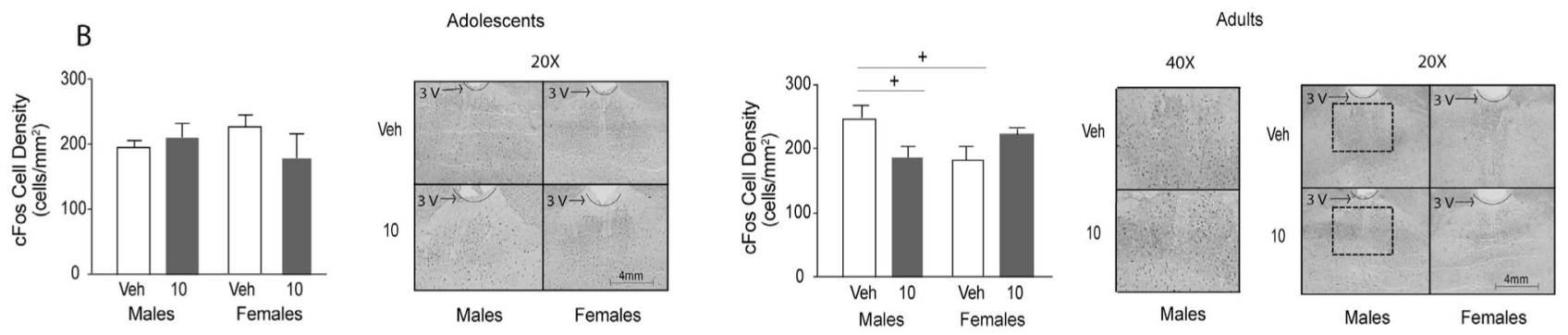

Fig. 3.

Orexin 1 receptor antagonist effects on c-Fos cell density in the central amygdala and posterior paraventricular nucleus of the thalamus. Adolescent data are shown in the left column, adult data in the right column. C-Fos cell density in the central amygdala (A) and posterior paraventricular nucleus of the thalamus (B) in vehicle- and SB334867-treated (10 $\mathrm{mg} / \mathrm{kg}$ ) groups in adolescent and adult rats were quantified and represented as average \pm SEM. Significant main effect of drug is indicated by * between drug groups on the $X$-axis. Following a significant interaction, significant post hoc tests are indicated by bars and * above the bars on the graphs, post hoc trends are indicated by + . Significant differences are represented as follows: ${ }^{*} p<0.05$ and $* * * p<0.001$. 
Adolescents
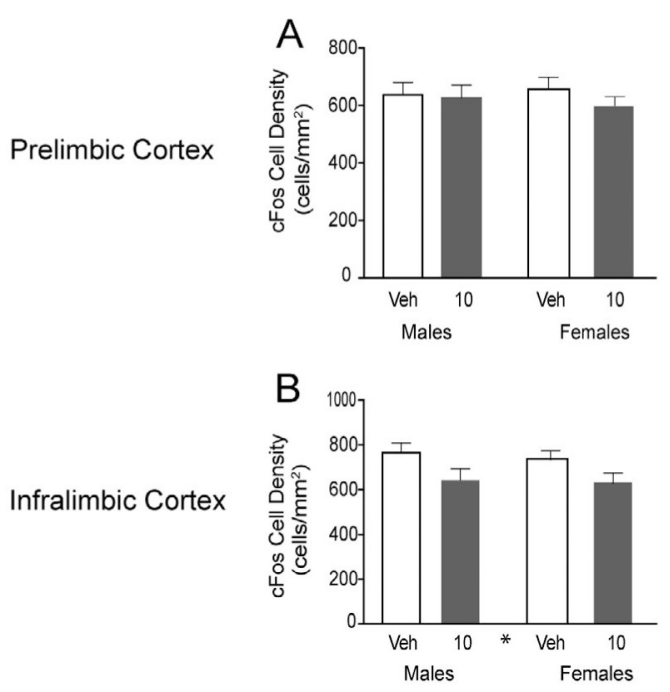

Locus Coeruleus

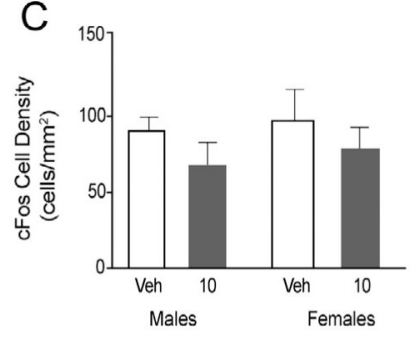

Basolateral Amygdala
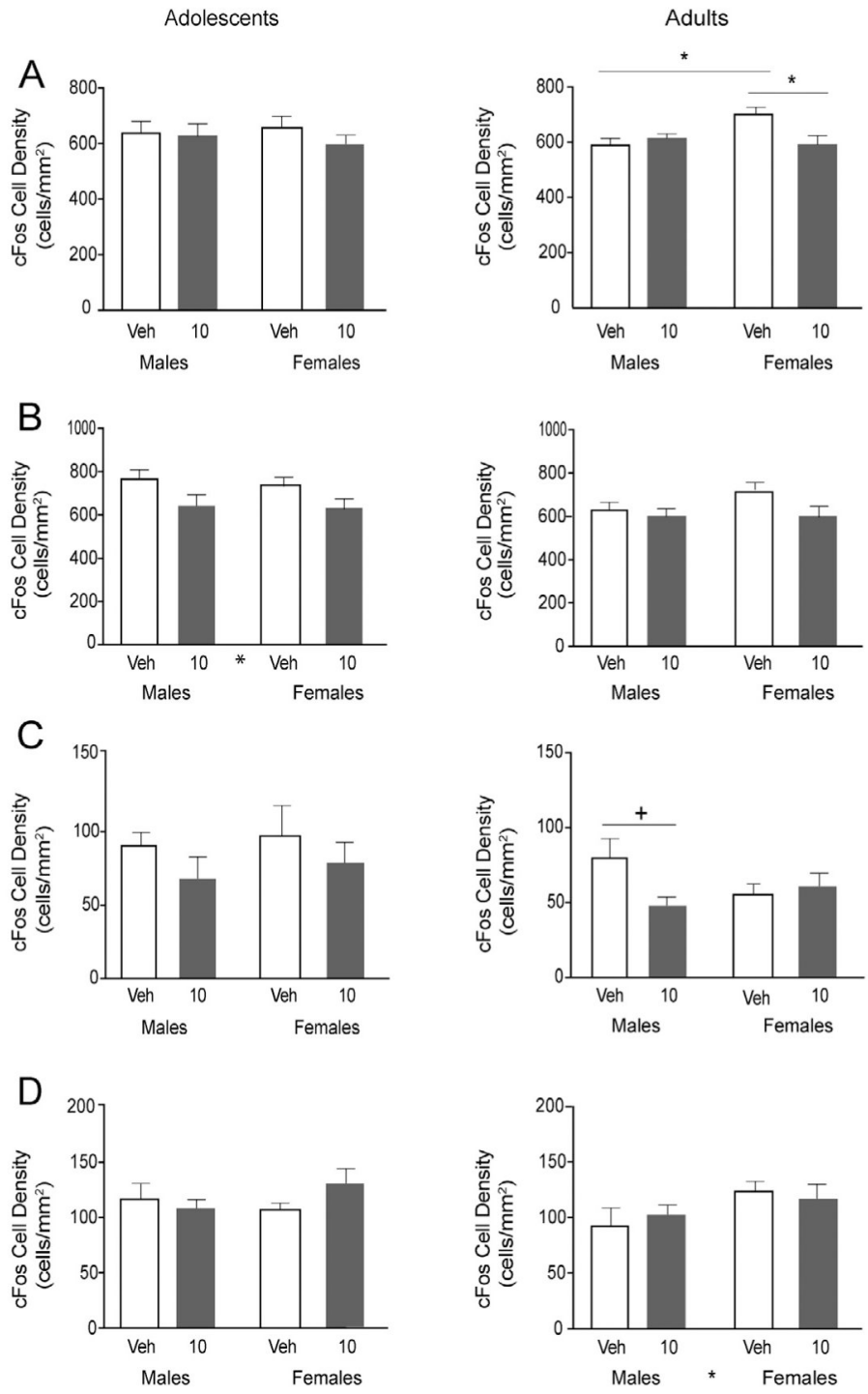

Fig. 4.

Orexin 1 receptor antagonist effects on c-Fos cell density in the prelimbic cortex, infralimbic cortex, locus coeruleus and basolateral amygdala. Adolescent data are shown in the left column, adult data in the right column. C-Fos cell density in the prelimbic cortex (A), infralimbic cortex (B), locus coeruleus (C) and basolateral amygdala (D) data in vehicle- and SB334867-treated $(10 \mathrm{mg} / \mathrm{kg})$ groups in adolescent and adult rats were quantified and represented as average \pm SEM. Significant main effect of drug is indicated by $*$ between drug groups on the $x$-axis. Following a significant interaction, significant post hoc tests are indicated by bars and * above the bars on the graphs, post hoc trends are indicated by + . Significant differences are represented as: $* p<0.05$. 


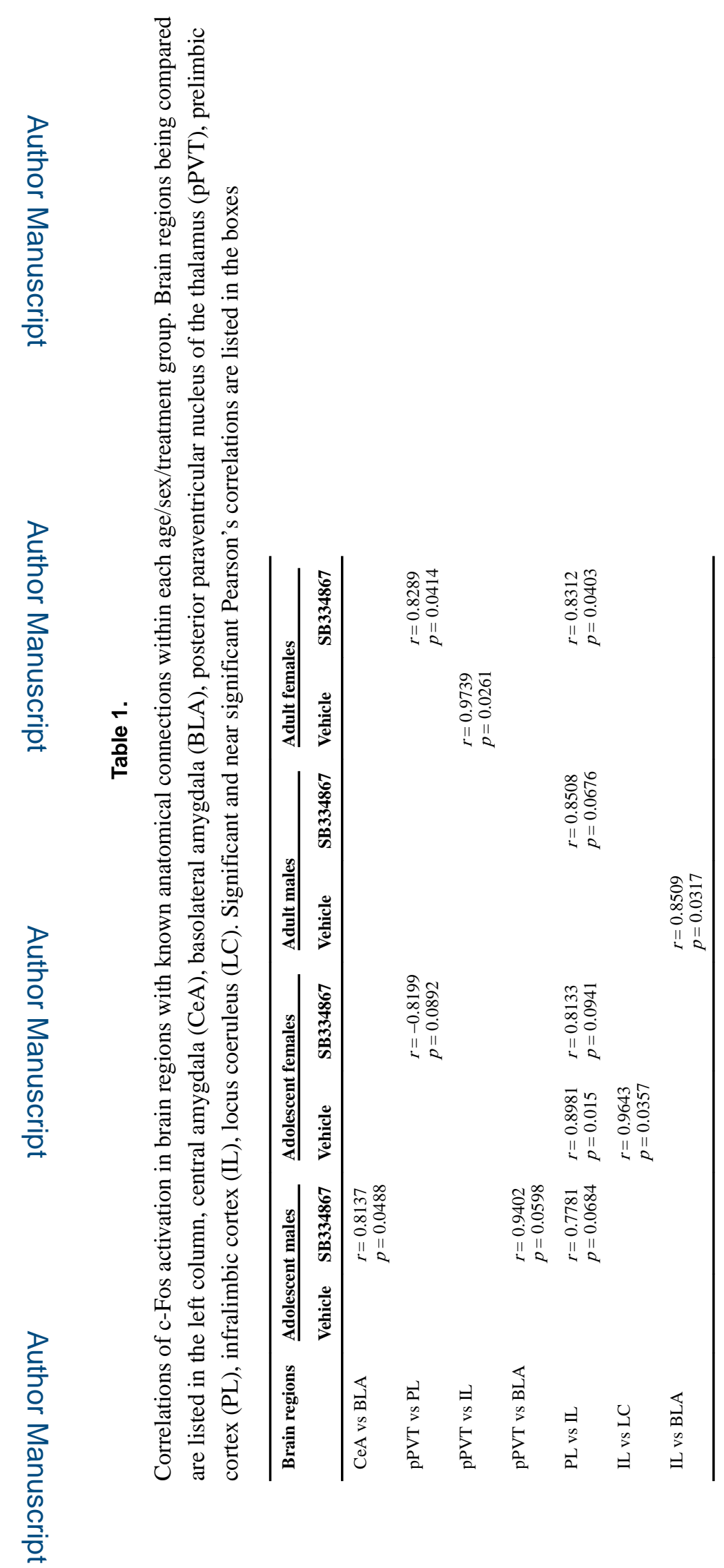

Neuroscience. Author manuscript; available in PMC 2019 January 24. 


\section{Table 2.}

Brain regions with orexin 1 receptor antagonist-induced changes in functional networks. Animals groups are listed in the first column and the brain regions compared between vehicle and SB334867 groups are listed in the second column. Results from Fisher's $z$-tests are listed in the third column with their associated $p$-values

\begin{tabular}{|c|c|c|}
\hline Animal groups & $\begin{array}{l}\text { Brain Regions } \\
\text { compared }\end{array}$ & $\begin{array}{l}\text { Correlation } \\
\text { comparisons }\end{array}$ \\
\hline Adolescent females & CeA vs BLA & $\begin{array}{l}z=-1.984 \\
p=0.047\end{array}$ \\
\hline Adult females & pPVT vs IL & $\begin{array}{l}z=2.522 \\
p=0.012\end{array}$ \\
\hline Adult females & pPVT vs PL & $\begin{array}{l}z=1.937 \\
p=0.053\end{array}$ \\
\hline Adult males & IL vs BLA & $\begin{array}{l}Z=-1.846 \\
p=0.065\end{array}$ \\
\hline
\end{tabular}

